\title{
CAN THE STOCHASTIC EQUILIBRIUM JOB SEARCH MODELS FIT TRANSITION ECONOMIES?
}

\author{
Marcin WOŹNIAK \\ (Received: 2 April 2014; revision received: 27 February 2015; \\ accepted: 10 March 2015)
}

The aim of this study is to apply the stochastic job search framework to the analysis of three transition economies (Poland, Hungary, and the Czech Republic). Two versions of equilibrium unemployment models have been developed resembling Mortensen and Pissarides' models, namely the dynamic and stochastic models. The dynamic model's properties were briefly examined by evaluating the Jacobian matrix and plotting the phase plane of the economy. In the primary analysis of the stochastic model, job destruction decisions are endogenous as a response to random productivity changes. A martingale, i.e. a discrete-space version of the geometric Brownian motion with the drift and volatility parameter, was used to enable fluctuation of endogenous variables and to perform numerical simulations. The results are promising, although ambiguous in some points, e.g. the main model-generated time-series are close to the empirical time-series, including reasonable fluctuations, correlation signs, and autocorrelations. However, the model was unable to capture some subtle differences in productivity and job destruction rate series across the countries, which is its main limitation.

Keywords: business cycle, endogenous destruction, equilibrium unemployment, stochastic process, wage dispersion

JEL classification indices: E32, J31, J63, J64

Marcin Woźniak, PhD student at the Department of Labour and Social Policy, Poznan University of Economics, Poland. E-mail: wozniac@gmail.com 


\section{INTRODUCTION}

Labour market analysis in a frictional environment has become the mainstream in modern economics due to the development of the search theory. The equilibrium unemployment model of Diamond, Mortensen, and Pissarides has been developed since the 1980s and won the Nobel Prize in 2010. As a consequence, the popularity of job search models rose significantly. There is a wide range of studies incorporating equilibrium unemployment models in analysing the real business cycle (eg. Nakajima 2012), economic growth (eg. Acemoglu 2011), fiscal policy (eg. Gomis-Porqueras 2010), and labour market policy (Michaillat 2012). The best-known problem identified by these studies is the fact that tiny variations of endogenous variables occur, which do not match historical facts. Another problem that has been the subject of a heated debate is the selection and setup of the stochastic process which drives the fluctuations of endogenous variables over time.

Mortensen - Pissarides (1994) introduced a matching framework with a job destruction decision made by companies. The authors introduced aggregate productivity shocks as a three-state Markov chain and calibrated the model to fit US labour market historical data. They proved that productivity dispersion is connected with job creation and job destruction decisions. The authors found the model's fluctuation to be reasonably consistent with the US data. Shimer (2005) criticised the Mortensen-Pissarides model as being unable to imitate large vacancy-unemployment fluctuations that are characteristic of the real business cycle due to the wage-absorbing shock attribute. His criticism emphasised the negative role of the Nash solution to the bargaining problem. As an alternative, he proposed more rigid wages. Shimer developed the discrete space process, which asymptotes the random walk process to include stochastic shocks in the model. A considerable part of Shimer's paper is devoted to a reliable model calibration procedure based on empirical data. By contrast, Hagedorn - Manovskii (2008) proposed an alternative to Shimer's way of calibrating the parameters, which has allowed the model to generate considerable fluctuations in unemployment and labour market tightness. The authors approximated random changes in productivity through a 35-state Markov chain. They found that the worker's bargaining power should be relatively low in order to restore model efficiency. Another means to enlarge fluctuations was to set the unemployment benefits value very close to average productivity. As a result, the estimates were close to those observed in the historical data. In our opinion, their calibration procedure has other weaknesses and the results are in conflict with the reality of transition economies. 
Most papers taking the stochastic equilibrium unemployment framework into consideration concentrate on the US economy, which is in many ways completely different from European economies. There are only a few studies which have applied the job search framework to the analysis of European transition economies (e.g. Lamo et al. 2011), but there are no papers which incorporated the stochastic search model to these countries. This paper is the first to contribute to this literature.

The aim of this paper is twofold; first, it wants to highlight the role of the stochastic process as a significant factor influencing the results of numerical simulations; second, it wants to investigate whether the stochastic equilibrium unemployment model with endogenous job separations can match the Polish, Hungarian, and Czech labour markets if a reasonable calibration strategy is used. A historical period covering alternating business cycles in the selected countries ${ }^{1}$ (CEPR 2014) and capturing the influence of the Great Recession was selected.

The transformation process began in these three countries ${ }^{2}$ at the beginning of the 1990s, after years of the functioning of a centrally planned economy and the strong impact of Soviet totalitarianism. Poland, the Czech Republic and Hungary started from a similar level of socio-economic development, but after two and a half decades, the differences are already visible. These phenomena also concern labour market characteristics and have resulted in significant differences in certain indicators. Considering the above, the main research question is this: What will be the performance of the stochastic equilibrium unemployment model in replicating labour markets in different transition economies?

There are some important elements that distinguish the model that is presented in this paper from the canonical Mortensen-Pissarides framework (MP). The most frequent procedure is to use a multi-state Markov chain. The present author decided to choose a martingale, i.e. the geometric Brownian motion (GBM). Prat (2006) suggested that the GBM is a proper tool to generate large fluctuations as well as proper correlation signs of key labour market variables. Prat assumed the one-parameter stochastic Wiener process and focused mainly on the job destruction rate and on productivity analysis. By contrast, this paper incorporates a discrete-time version of the geometric Brownian motion with the drift and volatility parameter.

1 Recent studies point to a high level of correlation between the business cycles of old and new EU members (Iossifov 2014). The Center of Economic Policy Research (CEPR) indicates the existence of real business cycle in the European Union, with a recession starting in the first quarter of 2008 and a turnaround which began in the second quarter of 2009.

2 Although some aspects of system change can be regarded as finished in these countries (free market), others are still in progress (especially socio-cultural changes). The latter influence the former and this implies that the transition process, in a broad sense, has not yet finished. 
A unique calibration procedure based on an analysis of real data was carried out for each country. The strategy was to compare and evaluate the set of endogenous variables generated by the stochastic model. Making job-worker separation decisions endogenous allowed the author to observe productivity and job destruction fluctuations in a single model run, as both variables were computed simultaneously. All numerical simulations were conducted using open-source software. ${ }^{3}$

The time-series generated by the model are coherent for certain key variables across the three countries (negative vacancy-unemployment correlation, negative job-finding-job-destruction rate correlation; considerably large data deviations; high autocorrelations). However, a deeper analysis shows some malfunctions, which are visible especially in contradictory correlations in productivity and job destruction rate. Wage dispersion analysis shows that the model fits well for Poland, but moderately for the Czech Republic, and the Hungarian distribution is biased and overestimated.

The structure of this paper is as follows: in Section 2, the model's theoretical structure was approached and solved for the stationary equilibrium. Dynamics were also added to the model, then the phase plane of the economy was plotted and evaluated. Section 3 presents the time series for the Polish, Hungarian, and Czech labour market between Q1 of 2000 and Q1 of 2014. In Section 4, the analytical model was approached and the stochastic process was implemented to enable fluctuations of endogenous variables. Next, structural parameters were calibrated with historical data and the author's own estimations were made in order to obtain values in a steady-state economy. In Section 5, a job output perturbation was initiated as the discrete-time version of the geometric Brownian motion with the drift and volatility parameter, and a benchmark data set was generated. Section 6 concludes the study and indicates important directions for further research.

\section{THE ECONOMY}

Our model draws upon Mortensen - Pissarides (1994, 1999). In order to keep it realistic, the job destruction process was made endogenous, as suggested by Davis et al. (1998). In accordance with Pissarides (2000) and Mortensen (2005) random productivity changes were introduced which govern job creation and job destruction conditions. First, some customary assumptions were made: The economy is inhabited by a fixed number of workers who are randomly distributed on

3 The Python Programming Language with suitable scientific libraries was applied. Python was used as an alternative to expensive commercial computing environments as MATLAB. The codes can be sent on request via email. 
the unit length interval. Time is continuous and workers discount the future at an exogenous rate $r$. Their lifespan is infinite and the consumption of homogeneous goods is linear. They are also risk neutral and have the same preferences. To keep the model as simple as possible, neither search intensity, nor any policy instruments are included.

Workers can be either employed or unemployed. If unemployed, a worker is seeking a job and receives unemployment benefit $b>0$. If employed, the worker earns wage $w$, but cannot search for a job. Each firm can post one vacancy. The supply of jobs is infinite. All firms are risk neutral and discount the future at the same rate as workers do.

Jobs are heterogeneous with respect to the stochastic productivity process. When a firm and a worker match, production starts. Jobs can have different levels of productivity, which is one of the endogenous model variables. Each job output combines two components, $p$ and $x ; p$ is the element which is common to all jobs in the economy and $x$ is stochastic and randomly distributed by the cumulative distribution function (CDF) $F(x)$ from a known continuous distribution $\forall x \in[0,1]$. When a shock hits the job at the exogenous Poisson rate, the new $x$ changes productivity $p$ and the firm must decide whether to continue the match or not. When $p$ falls below a certain endogenous reservation threshold $R$, the job is destroyed because it becomes unprofitable for the entrepreneur. As a result, changes in productivity follow a stochastic, persistent, memory-less Markov process. All jobs start producing at productivity $p=1$. The job collapses when productivity falls below $p<R$. A firm can enter the labour market and open new jobs without any cost. Finally, it is assumed that the value of the job output exceeds the value of the unemployment benefit $p>b$.

\subsection{Labour market}

A frictional, non-Walrasian labour market is considered. Matching between firms and workers is time-consuming. There is a firm's cost $c$ of posting a vacancy. The lack of coordination and information as well as the heterogeneity of workers and vacancies both increase the transaction costs of the job/worker search and match.

Labour market frictions are modelled through the matching function which represents new matches $M$ as a function of vacancies $v$ and workers $u$ :

$$
m=M(u, v) \text {. }
$$

Some additional assumptions are necessary. The matching function is increasing and concave in both arguments: $\frac{\delta M}{\delta u}>0, \frac{\delta M}{\delta u}>0$, and has decreasing marginal 
returns $\frac{\delta^{2} M}{\delta^{2} u}>0, \frac{\delta^{2} M}{\delta^{2} u}>0$. It is convenient to assume constant returns to scale the degree of homogeneity of $M$ is one.

Matches are formed in accordance with the Poisson process, with meeting rates $\tau_{w}=\frac{m(u, v)}{u}$ for workers and $\tau_{f}=\frac{m(u, v)}{v}$ for firms. Homogeneity of degree one allows us to write the $\frac{v}{u}$ relationship as one variable $\theta$, which is interpreted as labour market tightness. Both rates depend only on $\theta: \tau_{w}=M(1, \theta) ; \tau_{f}=M\left(\frac{1}{\theta}, 1\right)$.

When the firm and worker match, they produce until separation occurs. At the exogenous Poisson rate $\sigma$, the job output changes, and when it falls below the reservation threshold $R$, the job is destroyed. The evolution of the unemployment rate can thus be expressed as

$$
\dot{u}=\sigma G(R)(1-u)-\tau_{w} u .
$$

Unemployment dynamics can be written as the difference between the new matches and the flow into unemployment. It is worth noting that in the equilibrium, these two flows must be equal, which determines the steady-state unemployment ratio:

$$
\sigma G(R)(1-u)-\tau_{w} u .
$$

So far, it can be observed that $\tau_{w}$ depends on $v$, which is endogenous. To obtain the vacancy equation, we must first characterise both the firm's and workers' profits, which determine the wages in the economy. The labour market is frictional, so we can assume that the firm and workers have some bargaining power. None of the agents can be replaced instantaneously. In the MP job search model, wages are determined through game theory and the Nash solution.

\subsection{Firms}

The present discounted value of match at the given productivity is $\neq 1 \geq x \geq R$ as $J(x)$. This value is time-dependent, as is shown in the next section; however, in a steady state, it does not need to be taken into account. Therefore, $J$ must satisfy the following Bellman equation:

$$
r J(x)=p x-w(x)-\sigma \int_{R}^{1} J(s) d G(s)
$$

where $w(x)$ is the wage at the given job productivity and $s$ is the new random productivity level after a shock. The discount rate $R$ suggests that the value of remaining in a match is considered to be the flow. It can be interpreted (4) as follows: the flow income of the firm equals the total production minus wage paid to workers and the risk of job destruction if $s<R$. When a shock hits, employees 
either resign from their income and start producing with new $J(s)$ or a breakdown occurs.

The value of a vacant job is

$$
r V=-c+(J(1)-V) \tau_{f}
$$

Hence, this value consists of the exogenous cost of posting a vacancy and the chance of a profit in the case of a match with a worker. Note, that all jobs start with maximum productivity $x=1$. It might be convenient to write down the free entry condition $V=0$, which leads to

$$
J(1)=c p\left(\tau_{f}^{-1}\right) .
$$

Equation (5) is known as the job creation condition. It implies that a firm has no cost at entering the market and that all new jobs are created at maximum productivity $x=1$.

\subsection{Workers}

We can write similar value equations for matched workers at a given level of job productivity. In this case, the Bellman equation looks as follows:

$$
r W(x)=w(x)+\sigma \int_{R}^{1} W(s) d G(s)+\sigma G(R) U-\sigma W(x) .
$$

In this case, workers prefer to stay in a match as long as they receive flow $W(x)>U$, where $U$ is the value of unemployment.

When a worker becomes unemployed, he or she starts looking for a job. For a job seeker, the value function turns into:

$$
r U=\tau_{w}(W(1)-U)+b
$$

where $b$ can be the unemployment benefit, the income from informal market activities, or simply the value of leisure. The value of unemployment for a job seeker consists of some gains from being unemployed and the probability of receiving new income in case of finding a job. 


\subsection{Wages ${ }^{4}$}

The above values are determined by wages, which are paid in the case of a jobworker match. A necessary assumption for the match to exist is $W(x)-U \geq 0$ and $J-V \geq 0$, as both agents must profit from the cooperation. According to the Nash solution, wage is the worker's share of surplus established in the bargaining process. Thus, we can write the first-order condition as

$$
W(x)-U=\beta(J(x)+W(x)-V-U
$$

where $\beta$ denotes the bargaining power of the worker and $0>\beta>1$ and $W(x)-U=$ $\beta\left(W(x)-U+\int(x)-V=U+\beta S\right.$. Note, that firms destroy all jobs with productivity lower than

$$
J(R)=0 .
$$

We can now make use of (7) and the free entry condition (5) and substitute these expressions into (6):

$$
r U=\frac{\beta \theta p c}{1-\beta}+b
$$

Substituting the Bellman equation (4) and (3) into (7) and making some rearrangements results in

$$
w(x)=\beta p x+r U(1-\beta) .
$$

Deriving the wage is now straightforward: combine (9) and (8) to obtain

$$
w(x)=\beta p(x+c \theta)+b(1-\beta) .
$$

(13) is the equilibrium equation for wages, which is one of the key equations of the model.

\subsection{Solving the model ${ }^{5}$}

Both the job creation and job destruction condition are established in this step as being the further main equations of the modelled economy. To solve the model, it is required to use (13) and substitute it to (4) in order to get:

$4 \quad$ Mathematical appendix with detailed wage derivations is available upon request.

5 Mathematical appendix with detailed model solution derivation is available upon request. 


$$
r J(x)=p x-\beta p(x+c \theta)-b(1-\beta)-\sigma J(x)+\sigma \int_{R}^{1}(J(s) d G(s)
$$

Validate (14) at the threshold productivity level $(x=R)$ :

$$
(r+\sigma) J(R)=p R-\beta p(R+c \theta)-b(1-\beta) \sigma \int_{R}^{1} J(s) d G(s)=0 .
$$

Come back with the RHS of (15) and subtract from (14):

$$
(r+\sigma) J(x)=p(1-\beta)(1-R) .
$$

Now we can derive the job creation condition. It should be remembered that all new jobs are created at the highest productivity and make use of (16) to obtain

$$
c\left(\tau_{f}^{-1}\right)=\frac{p(1-\beta)(1-R)}{r+\sigma} .
$$

(17) is the job creation condition which gives a unique equilibrium value for labour market tightness.

To close the model, it is necessary to derive the job destruction condition. Take the value for $J(x)$ from (4) and insert it into (14) to get:

$$
(r+\sigma) J(x)=p x-\beta p(x+c \theta)-b(1-\beta)+\sigma \int_{R}^{1} \frac{p(1-\beta)(1-R)}{r+\sigma} d G(s) .
$$

Equation (18) is evaluated at the threshold productivity $R$. Below $R$, all jobs are destroyed. So:

$$
0=p R-\beta p(R+c \theta)-b(1-\beta)+\frac{p(1-\beta) \sigma}{r+\sigma} \int_{R}^{1}(s-R) d G(s) .
$$

After simplification, we obtain the next key equation of the search model with endogenous destruction:

$$
\mathrm{R}-\frac{\beta c \theta}{1-\beta}-\frac{b}{p}+\frac{\sigma}{r+\sigma} \int_{R}^{1}(s-R) d G(s)=0 .
$$

Formula (20) gives the reservation productivity $R$ in terms of $\theta$ and the model parameters. With (17), the solution can easily be obtained. Finally, we can add the last equation, which gives us the steady-state unemployment rate. Consider (2) and note that in the equilibrium $\dot{u}=0$. The result follows immediately:

$$
u=\frac{\sigma G(R)}{\sigma G(R)+\tau_{w}} .
$$

The model is now complete. 


\subsection{Digression: adding dynamics ${ }^{6}$}

To simplify derivation in this part, it could be assumed for a moment that the separation rate is exogenous. It is convenient to remember that $V=0$ to obtain a dynamic MP model and to track the main variables' paths $(w, \theta, u)$ out of the steady state. This assumption is valid during model adjustments out of the steady state because firms can open and close vacancies instantly all the time.

The second key variable $w$ is subject to similar conditions and can be adjusted immediately because its value depends on $J, V, W, U$, with the only determinants being $\tau_{w}$ and $\tau_{f}$ It turns out that the only state variable is $u$, which follows

$$
\frac{d u}{d t}=\sigma(1-u)-\tau_{w} u
$$

The dynamic value equation for a vacant job becomes

$$
r V=-p c+\tau_{f}(J-V)+\frac{d V}{d t} .
$$

For matched jobs one can write

$$
r J=p-w+\frac{d J}{d t}-\sigma J
$$

Similar equations can be written for unemployed and matched workers:

$$
\begin{aligned}
& r U=z-\tau_{w}(W-U)+\frac{d U}{d t}, \\
& r W=w-\sigma(U-W)+\frac{d W}{d t} .
\end{aligned}
$$

Remember that $W=\frac{d V}{d t}=0$ is also valid in a dynamic equilibrium and gives

$$
J=c\left(\tau_{f}^{-1}\right) .
$$

After rearrangements of (24) and inserting in (27), we get

$$
\frac{d J}{d t}=\mathrm{pc}(\mathrm{r}+\sigma)\left(\tau_{f}^{-1}\right)-\mathrm{p}+\mathrm{w} .
$$

6 To enrich the topic, some remarks on the dynamic version of the MP model have been added in this section, although analyses of transition economies were conducted with the endogenous job destruction model from Section 2.5. 
After differentiating (27) with respect to time, substituting into (28), and making use of the wage equation (18), we receive the dynamic formula for $\theta$ with one unknown:

$$
p c \tau_{f} \frac{d \theta}{d t}=(r+\sigma) p c \theta-p+(1-\beta) b+\beta p(1+c \theta) .
$$

Arriving at both transition rates ${ }^{7}$ and making some rearrangements of (29) leads us into a set of two differential equations in two unknowns, $u$ and $\theta$ :

$$
\begin{gathered}
\frac{d u}{d t}=\sigma(1-u)-\theta^{1-\alpha} u, \\
\frac{d \theta}{d t}=\frac{r+\sigma}{\alpha} \theta-p \frac{\theta^{1-\alpha}(1-\beta)(p-b)}{c \alpha}+\frac{\beta \theta^{2-\alpha}}{\alpha} .
\end{gathered}
$$

The equilibrium can be characterised by linearising the system near points where $\frac{d u}{d t}=\frac{d \theta}{d t}=0$. Evaluating the Jacobian matrix at those fixed points leads us to

$$
J=\left|\begin{array}{ll}
\frac{\delta m}{\delta u} & \frac{\delta m}{\delta \theta} \\
\frac{\delta f}{\delta u} & \frac{\delta f}{\delta \theta}
\end{array}\right|=\left|\begin{array}{cc}
-\left(\theta^{1-\alpha}\right)-\sigma & -u \frac{\theta^{1-\alpha}(1-\alpha)}{\theta} \\
0 & \frac{\frac{r+\sigma}{\alpha} \theta^{1-\alpha} \alpha(1-\alpha)(p-b)(1-\beta)}{c \theta}+\frac{\theta^{(2-\alpha)} \beta(2-\alpha)}{\alpha \theta}
\end{array}\right| .
$$

The matrix eigenvalues are both real, with opposite signs, thus the equilibrium is saddle. Plotting the set of Equations (30) and (31) shows us the dynamic equilibrium model with adjustment paths.

The arrows indicate the directions of movements out of the steady state. Combining $\frac{d \theta}{d t}$ and $\frac{d u}{d t}$ determines the unique saddle path converging at the saddle point, which is shown in Figure 1. The intersection of the nullclines determines the equilibrium point in this simple economy. Note that $\frac{d \theta}{d t}$ is an unstable variable whose adjustment is immediate because it is independent of $u(31)$, which evolves slowly in time according to (30). In fact, $\frac{d \theta}{d t}$ depends only on $\theta$ and the model parameter. ${ }^{8}$ The fact that future-oriented firms create more vacancies at the present time in order to avoid difficulties connected with hiring new workers if the unemployment rate drops can be used as the economic reason (Pissarides 2011).

7 Transition rates depend on the Cobb-Douglas matching technology, which was described in Section 3.

$8 \quad$ The $\mathrm{V}=0$ condition forces $\theta$ to change instantaneously. 


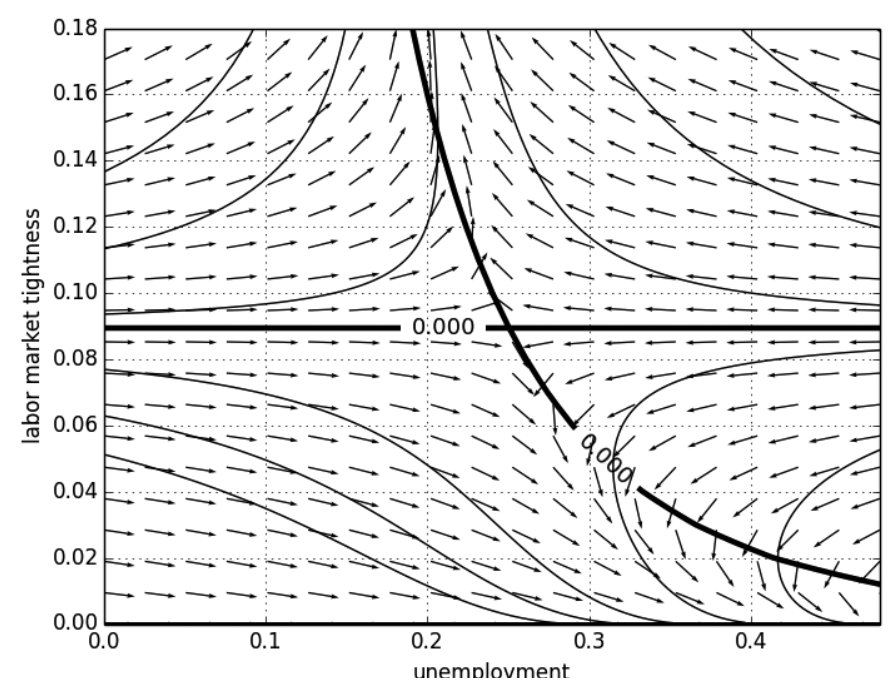

Figure 1. Phase plane of the modelled economy

Note: The following model parameters were set ${ }^{9}: \sigma=0.1, \sigma=0.1, \sigma=0.1, \sigma=0.1, \sigma=0.1, \sigma=0.1, \sigma=0.1$. To obtain trajectories, equations (30) and (31) were differentiated for different equilibrium values. Zero-growth isoclines (nullclines) are marked with a bold line - they are the contour plot of Eqs. (30) and (31).

Source: Own calculations.

\section{DATA}

The time period between Q1 2000 and Q1 2014 was chosen because it corresponds to the real business cycle in EU-27 (Iossifov 2014). Unfortunately, the year 2000 is the lower limit of data availability for most former Soviet-bloc countries, thus I could not analyse a longer period. The data frequency is quarterly, which implies 57 time points. The following labour market series were used in this paper: unemployment rate, vacancy rate, job-finding rate, vacancy/unemployment ratio (labour market tightness), separation rate, labour productivity, and wages.

Empirical indicators, which correspond to the endogenous model variables, were all taken from national Labour Force Surveys, administrative data extracted from Public Employment Services, and national accounts (as shown in Table 1). The vacancy ratio was calculated according to the formula $\frac{v}{e+v}$, where $v$ is the number of vacancies and $e$ is the number of employed people in the economy.

9 The values of the parameters were set based on the example in Romer (2012). 
Table 1. Data sources

\begin{tabular}{|c|c|c|}
\hline Data & Survey & Source \\
\hline \multicolumn{3}{|l|}{ Unemployment } \\
\hline \multicolumn{3}{|l|}{ Employment } \\
\hline Active population & Labour Force Survey (LFS) & http://epp.eurostat.ec.europa.eu/ \\
\hline \multicolumn{3}{|l|}{ Unemployment rate } \\
\hline \multicolumn{3}{|c|}{ Short-term unemployed } \\
\hline Job vacancies & $\begin{array}{l}\text { Public Employment Services, } \\
\text { (PES) OECD }\end{array}$ & http://stats.oecd.org/ \\
\hline Wages & OECD annual reports & \\
\hline New hires & (PES) & $\begin{array}{l}\text { http://eu.munka.hu/ (Hungary) } \\
\text { http://www.mpsv.cz/ (Czech } \\
\text { Republic) } \\
\text { http://www.psz.praca.gov.pl/ } \\
\text { (Poland) }\end{array}$ \\
\hline $\begin{array}{l}\text { Labour productivity } \\
\text { per person }\end{array}$ & National accounts & http://epp.eurostat.ec.europa.eu \\
\hline
\end{tabular}

The unemployment rate and productivity were extracted directly from the statistical sources.

Quarterly job-finding $\left(\tau_{w}\right)$ and separation $(s r)$ rates were calculated according to formulas implied by the matching function $\tau_{w}=\frac{M}{u} \wedge s r=u_{e}^{u^{5}}$, where $M$ means new hires, $u^{5}$ denotes the number of the newly registered unemployed (with unemployment duration less than one quarter), and $e$ is the stock of the employed in the economy. Both rates were plotted in Figure 2.
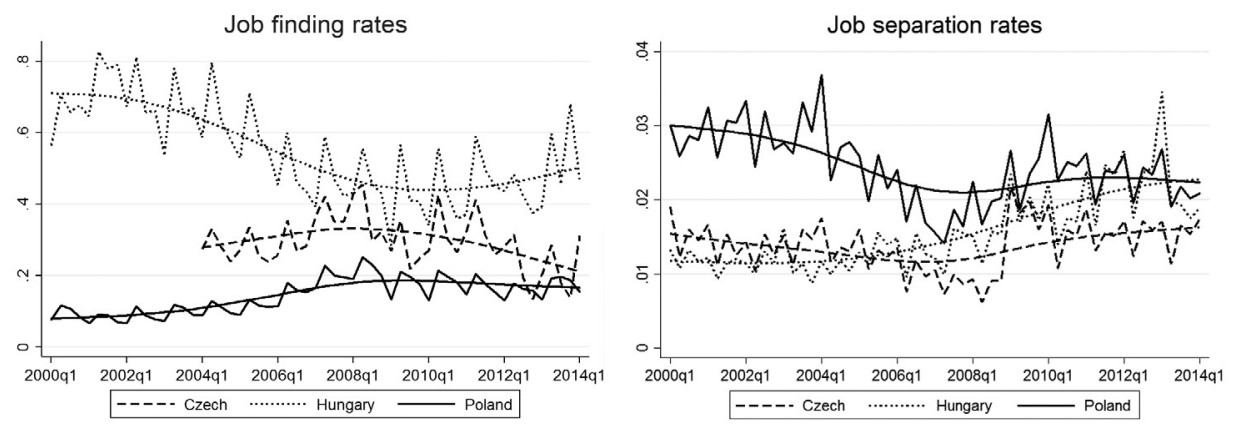

Figure 2. Empirical quarterly job-finding and separation rates with trends

Source: Rates for each economy were computed using data extracted from LFS and PES. For the Czech Republic, $\tau_{\mathrm{w}}$ could be computed starting from $2004 \mathrm{q} 1$ because of the limited availability of $M$ time-series. The trend was calculated with the Hodrick-Prescott filter. 

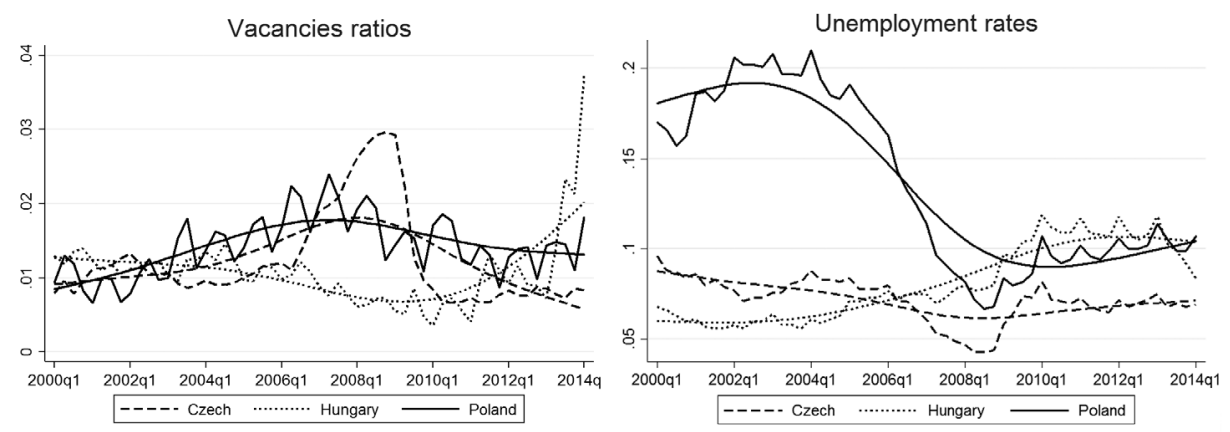

Figure 3. Vacancies, unemployment and trends

Source: Unemployment rates are quarterly LFS data; vacancies ratios are constructed according to the formula based on LFS. The trend is estimated with the Hodrick-Prescott filter.

The job-finding and separation rates are strongly procyclical, but the job-finding rate is about 20 times more volatile than the separation rate. The average job-finding rates for the selected period were 0.55 for Hungary, 0.14 for Poland, and 0.29 for the Czech Republic. It can be noticed that in 2000 there were huge differences in job-finding rates across the countries, but this disparity decreased significantly until 2014 . The average separation rates were quite similar, with values of 0.016 for Hungary, 0.024 for Poland, and 0.014 for the Czech Republic.

The inverses of the finding rates $\left(1 / \tau_{w}\right)$ give an average unemployment duration of 1.8 quarters for Hungary, 7 quarters for Poland, and 3.5 quarters for the Czech Republic, which roughly corresponds to the empirical data (Eurostat LFS). Figure 3 plots the two key variables: vacancies and unemployment.

The average vacancy ratio estimated for Hungary was $0.010,0.014$ for Poland, and 0.013 for the Czech Republic. The low value of this indicator implies a large number of job seekers per one registered vacant job, i.e. 10 for Hungary, 12 for Poland, and 7 for the Czech Republic.

An enormous change of unemployment stock during the years 2000-2008 can be noticed in Poland - the unemployment rate fell from $20 \%$ to $7 \%$. In Hungary and the Czech Republic, this indicator was never above 12\%. Since 2009, unemployment rates started rising slowly in all of the countries and the values of the indicator caught up with one another. The average unemployment rates were 13.6\% for Poland, $8.1 \%$ for Hungary, and 6.8 for the Czech Republic.

Post-transition economies are known for low labour productivity, which is the consequence of, inter alia, the previous totalitarian system with its centrally planned economy. However, a dynamic rise of the indicator can be noticed during the last decade. Figure 4 plots labour productivity in the Czech Republic, Poland, and Hungary as an average per worker. 


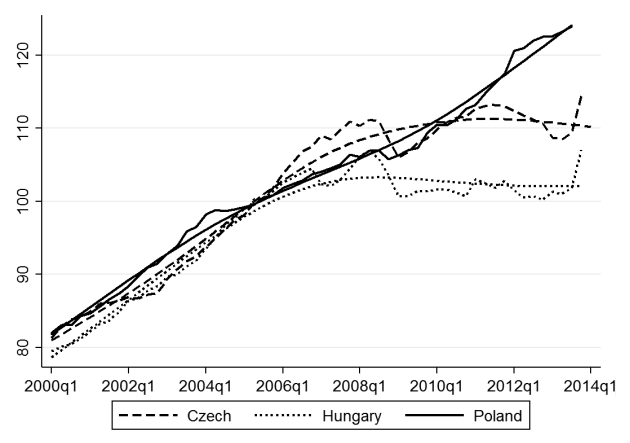

Figure 4. Labour productivity per worker

Source: Eurostat national accounts with normalisation $2005=100$. The trend is the Hodrick-Prescott filter with $\lambda=1600$.

Productivity growth was significant. Over the 14-year period Eurostat reported a $42 \%$ increase for Poland, a 33\% change for the Czech Republic, and a $28 \%$ growth in Hungary. Table 2 presents our parameter estimates based on the time series reported above.

Labour market tightness $\theta$ shows the highest variation. This variable is also considerably negatively correlated with unemployment and positively correlated with vacancies. Rising vacancies increase labour market tightness, whereas rising unemployment reduces labour market tightness. Fluctuations of vacancies, calculated as standard deviations from the HP filter trend component, are similar to the 0.25 deviation for the Czech Republic and the 0.23 deviation for Hungary and Poland. The rest of the variables display a large scale of variability, with 0.1 to 0.51 deviation and 0.89 to 0.99 autocorrelation.

Unemployment generates a negative correlation with vacancies, ${ }^{10}$ labour market tightness, the job-finding rate, and productivity in all of the economies. The job destruction rate is positively correlated with unemployment and negatively correlated with the finding rate, labour market tightness, and vacancies. A negative relation between $\tau_{\mathrm{w}}$ and $d r$ is a well-known empirical fact for the US and for most EU countries (Mortensen - Pissarides 1994; Shimer 2005), which can also be noticed in transition economies. Productivity with a 0.11 to 0.32 standard deviation is negatively correlated with unemployment. The correlation of other time-series varies across the countries and no pattern could be found. For

10 The negative relation of the $v-u$ series can be graphically presented as the Beveridge Curve. Analysis of the curve has become a significant part of labour economics, as we can make conclusions about the condition of the economy and the phase of the business cycle. 
Table 2. Correlation matrices, autocorrelation, and standard deviations of empirical series

\begin{tabular}{|c|c|c|c|c|c|c|}
\hline $\begin{array}{l}\text { Czech } \\
\text { Republic }\end{array}$ & $v$ & $u$ & $\theta$ & $\tau_{\mathrm{w}}$ & $d r$ & $p$ \\
\hline$v$ & 1 & & & & & \\
\hline$u$ & -0.57 & 1 & & & & \\
\hline$\theta$ & 0.98 & -0.7 & 1 & & & \\
\hline$\tau_{\mathrm{w}}$ & 0.91 & -0.73 & 0.94 & 1 & & \\
\hline$d r$ & -0.99 & -0.45 & -0.95 & -0.86 & 1 & \\
\hline$p$ & -0.43 & -0.47 & -0.28 & -0.21 & 0.54 & 1 \\
\hline Std. Dev. & 0.25 & 0.1 & 0.31 & 0.13 & 0.12 & 0.1 \\
\hline Autocorr & 0.95 & 0.96 & 0.95 & 0.91 & 0.94 & 0.95 \\
\hline Hungary & $v$ & $u$ & $\theta$ & $\tau_{\mathrm{w}}$ & $d r$ & $p$ \\
\hline$v$ & 1 & & & & & \\
\hline$u$ & -0.53 & 1 & & & & \\
\hline$\theta$ & 0.88 & -0.87 & 1 & & & \\
\hline$\tau_{\mathrm{w}}$ & 0.80 & -0.91 & 0.97 & 1 & & \\
\hline$d r$ & -0.42 & 0.98 & -0.79 & -0.84 & 1 & \\
\hline$p$ & -0.67 & -0.31 & -0.18 & -0.07 & -0.36 & 1 \\
\hline Std. Dev. & 0.23 & 0.25 & 0.36 & 0.18 & 0.25 & 0.23 \\
\hline Autocorr & 0.95 & 0.97 & 0.98 & 0.97 & 0.96 & 0.87 \\
\hline Poland & $v$ & $u$ & $\theta$ & $\tau_{\mathrm{w}}$ & $d r$ & $p$ \\
\hline$v$ & 1 & & & & & \\
\hline$u$ & -0.76 & 1 & & & & \\
\hline$\theta$ & 0.92 & -0.95 & 1 & & & \\
\hline$\tau_{\mathrm{w}}$ & 0.87 & -0.97 & 0.99 & 1 & & \\
\hline$d r$ & -0.97 & 0.85 & -0.96 & -0.93 & 1 & \\
\hline$p$ & 0.70 & -0.89 & 0.86 & 0.92 & -0.79 & 1 \\
\hline Std. Dev. & 0.23 & 0.31 & 0.51 & 0.3 & 0.12 & 0.11 \\
\hline Autocorr & 0.95 & 0.98 & 0.97 & 0.97 & 0.99 & 0.94 \\
\hline
\end{tabular}

Source: Own calculations. All variables are reported in logs and HP-filtered with $\lambda=1,600$.

example, a significant positive relation between productivity and the finding rate can be observed in Poland, while in the Czech Republic and Hungary this relation is slightly negative. Such differences are numerous, mainly in productivity with other series relations, thus showing the diversity of the three labour markets. 


\section{CALIBRATION AND COMPUTATION}

In order to continue analysis, the matching technology needs to be described. The matching function must be continuous, at least twice differentiable, and have constant returns to scale. Moreover, the Inada conditions ${ }^{11}$ need to be fulfilled (Mortensen - Nagypal 2007). The Cobb-Douglas production function meets all of these requirements. It can assume the following, standard form:

$$
M(u, v)=A u^{\alpha} v^{1-\alpha} .
$$

Now, using the homogeneity of degree one condition we can define both meeting rates: $\tau_{w}=A \theta^{1-\alpha}$ and $\tau_{f}=A \theta^{-\alpha}$. Given equation (19), it is easily visible that both rates $\tau_{f}$ and $\tau_{w}$ depend only on $\theta . \tau_{f}$ is decreasing in $\theta$ and $\tau_{w}$ is increasing in $\theta$. This implies a unique equilibrium value for $u$.

The Markov process was used (the GBM), which drives random productivity changes over time, to add necessary fluctuations to the model. The process is a martingale and its general definition can be characterised by the following stochastic differential equation: ${ }^{12}$

$$
d S(t)=\frac{\mu S(t)}{d t}+\delta S(t) d W(t)
$$

where $W(t)=W(t)-W(0) N(0, t)$ is the standard Brownian process, $\mu$ is the drift parameter and $\delta$ is volatile. It was assumed that these are constant parameters. We can compute the solution for initial value $S(0)$, which is ${ }^{13}$

$$
S(t)=S(0) e^{\left(\left(\mu-0.5 \delta^{2}\right) t+\delta W(t)\right)} .
$$

Thus, it can be assumed that the stochastic productivity component $x$ follows $S$, and productivity is determined by the exponential Brownian process as the implication. The author here decided to choose GBM, given the proven fact that it can generate a considerable volatility in the $v / u$ ratio (Prat 2006). In the computations, a discrete-space version of the GBM was used, with every period obtaining a new productivity value from the lognormal distribution. ${ }^{14}$

The next key step to find out whether the model can replicate Polish, Czech, and Hungarian labour market time-series was to set up structural model parameters.

$11 \quad$ If $f(\theta)=M(\theta, 1)$, then $f(0)=0, f^{(\infty)}=\infty, \frac{d f}{d \theta}(0)=\infty$.

12 A detailed derivation of GBM can be found in several papers, especially those concerning finance, trade, and stock price analysis, e.g. Gatheral - Schied (2011).

13 An analytical solution was obtained by applying Ito's Lemma and taking the exponential of the formula obtained in the logs.

In the case of GBM, the logarithms of computed random variables are normally distributed. 
Note that the model presented here consists of 10 parameters which are as follows: the Poisson arrival rate of shocks $\sigma$, elasticity of the matching function with respect to unemployment $\alpha$, matching-function scaling parameter $A$, bargaining power parameter $\beta$, labour productivity $p$, unemployment benefit $b$, discount rate $r$, cost of posting a new vacancy $c$, volatility of the stochastic process $\mu$, and the so-called drift factor of geometric Wiener motion $\delta$, which is considered a long-term mean.

To solve the model for equilibrium values, the we started by normalising $p$ to 1 and set the model time to one quarter, which implied $r=0.012$ for all countries. The next parameter was the Poisson arrival rate of idiosyncratic productivity shocks $\sigma$. Calibration of this parameter requires some explanation. First, the author here computed the job destruction probability, with a slightly modified equation originally posted by Shimer: ${ }^{15} S_{t}=\frac{u_{t+1}^{s}}{e_{t}\left(1-0.2 F_{t}\right)}$, where $u_{t+1}$ is the number of the unemployed in the next period, $u_{t+1}^{s}$ is the number of the short-term unemployed, and $F_{t}$ is the probability of finding a job in a given period: $F_{t}=1-\frac{u_{t+1}-u_{t+1}^{s}}{u_{t}}$. Equations $S_{t}$ and $F_{t}$ are a linear approximation for the differential equations describing probabilities (see Becker - Clerc 2012 for details). Thus, on the basis of our data (Table 1), it was estimated that the average job destruction probability was 0.023 for Poland, 0.013 for the Czech Republic, and 0.015 for Hungary. In the model here not every shock is deadly, thus the author set $\sigma=0.092(4 \cdot 0.023)$ for Poland, $\sigma=0.052$ for the Czech Republic ( $4 \cdot 0.013)$, and $\sigma=0.060$ for Hungary $(4 \cdot 0.015)$. As a result, a random shock hits the job four times per quarter and changes its productivity according to the evolution of the GBM.

Next, matching function elasticities were computed for each economy. ${ }^{16}$ The estimated elasticity of the matching function with respect to unemployment was 0.30 for Poland, ${ }^{17} 0.35$ for Hungary, and 0.37 for the Czech Republic, which is relatively low. The worker's bargaining power $\beta$ was set to 0.5 . $\beta$ was adjusted with no empirical facts about the workers' bargaining power. It was based on a theoretical assumption about the symmetry of the Nash bargaining solution,

15 Originally, Shimer used monthly data to estimate job separation probability and assumed a two-week lag between losing the job and registration in the employment office. In this case, Shimer subtracted half of the probability of finding the job $\left(F_{t} \cdot 0.5\right)$ from separation probability. In the case of quarterly data, a two-week lag means 0.2 quarterly probability of finding the job $\left(F_{t} \cdot 0.2\right)$.

16 The simplest analytical shape of matching function was specified taking $\operatorname{logs}$ of (34): $\ln M=$ $\alpha \ln u+(1-\alpha) \ln v$. The linear regression model estimated for each economy: $\ln M=$ const + $\alpha \ln u+(1-\alpha) \ln v+\varepsilon$; data sources are specified in Table 1. Stationarity of series was tested with KPSS method.

17 More details about estimating the matching function and assessing the impact of labour market policy for the Polish economy can be found in Woźniak (2015). 
which implies that an unemployed person and the employer have an equal share in the negotiation process (Mortensen - Nagypal 2007).

The unemployment benefit $b$ is a controversial point of the search models' calibration (Hornstein et al. 2011). In this case, OECD data were used. The average 2000-2013 replacement ratio estimated for Poland was $0.55,0.59$ for the Czech Republic, and 0.74 for Hungary (OECD 2012). The equilibrium wages for these economies were $0.37,0.44$ and 0.42 , respectively. According to Shimer (2005), it is convenient to add some extra value here. Unemployed workers not only receive money transfers from PES, but gain the value of leisure or the value of working in the underground sector. Thus, $b$ was set according to the formula $b=$ replacement $_{\text {ratio }} \cdot$ equilibrium wage $^{+ \text {value }}$ of leisure. The value of leisure was arbitrarily set to $5 \%$ of the unemployment income. ${ }^{18}$ Finally, $b$ was set to 0.25 for Poland, 0.31 for the Czech Republic, and 0.36 for Hungary.

The next parameter which needed to be set up was the cost of opening a new vacancy $c$. The OECD unit labour cost indicator was used to calibrate the parameter (average values for 2000-2013). On the basis of data, $c$ was set to 0.587 for Poland, 0.589 for the Czech Republic and 0.637 for Hungary.

Parameter $\mu$ was adjusted to capture the average quarter labour productivity fluctuation in each of the economies from Q1 2000 to Q1 2014. After seasonal detrending, Eurostat observed a quarterly productivity fluctuation equal to $1.5 \%$ for Poland, $1.3 \%$ for the Czech Republic and $1.1 \%$ for Hungary. $\delta$ was adjusted to 0.42 for Poland, 0.33 for the Czech Republic, and 0.28 for Hungary, which was the value of job productivity growth observed in the Eurostat data over the selected period. The initial value of match-specific productivity was set to capture the average $v-u$ correlation as observed in the historical data.

The equilibrium computations of the baseline model show that key endogenous variables closely match the data, with a benchmark unemployment value of $13.7 \%$ for Poland, $8.1 \%$ for Hungary, and $7.1 \%$ for the Czech Republic. The computed job-finding and destruction rates were slightly overestimated as compared to the historical averages. The equilibrium vacancy ratios were between 0.06 and 0.1 , which is a higher value than the ratios observed in the registered data. Table 3 presents the model's endogenous variables' equilibrium values and averages of historical time-series.

18 The paper did not consider the questionable Hagedorn - Manovskii (2008) suggestion that unemployment benefits (the value of leisure) should be set close to productivity in order to enable a large fluctuation of endogenous variables. This assumption fails to correspond with the post-Soviet countries' labour market facts (bearing in mind that the OECD 2012 estimated replacement ratio was $0.25-0.36$ ). 
Table 3. Endogenous variables' equilibrium values and averages of empirical time-series

\begin{tabular}{llll}
\hline Mean value - data & & & \\
\hline & Poland & Hungary & Czech Republic \\
Unemployment rate & 0.137 & 0.081 & 0.071 \\
Vacancy ratio & 0.014 & 0.01 & 0.012 \\
Job-finding rate & 0.15 & 0.52 & 0.30 \\
Job destruction rate & 0.03 & 0.02 & 0.02 \\
\hline Equilibrium value - model & & & \\
\hline & Poland & Hungary & Czech Republic \\
Unemployment rate & 0.137 & 0.081 & 0.071 \\
Vacancy ratio & 0.10 & 0.06 & 0.07 \\
Job-finding rate & 0.58 & 0.67 & 0.60 \\
Job destruction rate & 0.06 & 0.05 & 0.04 \\
\hline
\end{tabular}

Source: Own calculations.

\section{SIMULATION RESULTS}

In the numerical simulations we used the model with endogenous job destruction as described in Section 2.5. The model generated the following indicators: unemployment rate, vacancy ratio, labour market tightness (v-u ratio), job-finding rate, job destruction rate, job productivity, and wages. Computations for each economy were performed according to the following procedure:

1) solve the model for equilibrium values,

2) create 57 time points equivalent to 57 quarters from Q1 2000 to Q1 2014 and fill them in with GBM results,

3) compute the vector of variables $u, v, \theta, \tau_{w}, s t, p, w$ for each time point,

4) take the log of data,

5) detrend data with the HP filter (with $\lambda=1600$ ),

6) append 57 computed data points to the matrix,

7) 10,000 iterations of steps $2-6$ to obtain representative results, and

8) final analysis.

The results are presented in Table 4. The results are promising, although ambiguous at some points.

The model produces moderate deviations of all endogenous variables, but these fluctuations are slightly too small to match transition economies. All of the generated variables, similarly to the historical facts, are highly auto-correlated 
with the first-level autocorrelation between 0.83 and 0.93 . The vacancy-unemployment correlations are roughly close to the empirical ones, with a -0.98 value for Poland, -0.67 for Hungary, and -0.81 for the Czech Republic. These results indicate that the model can generate a strong negative relationship between these variables and can imitate the behaviour of the Beveridge Curve. The model generated a strong negative correlation for unemployment-labour market tightness,

Table 4. Benchmark model simulation results

\begin{tabular}{|c|c|c|c|c|c|c|}
\hline $\begin{array}{l}\text { Czech } \\
\text { Republic }\end{array}$ & $v$ & $u$ & $\theta$ & $\tau_{\mathrm{w}}$ & $s t$ & $p$ \\
\hline$v$ & 1 & & & & & \\
\hline$u$ & -0.81 & 1 & & & & \\
\hline$\theta$ & -0.98 & -0.97 & 1 & & & \\
\hline$\tau_{\mathrm{w}}$ & 0.95 & -0.99 & 0.97 & 1 & & \\
\hline$s t$ & -0.2 & -0.26 & -0.55 & -0.73 & 1 & \\
\hline$p$ & 0.58 & -0.94 & -0.55 & 0.94 & -0.9 & 1 \\
\hline Std. Dev. & 0.07 & 0.1 & 0.16 & 0.13 & 0.04 & 0.06 \\
\hline Autocorr & 0.8 & 0.83 & 0.81 & 0.89 & 0.96 & 0.89 \\
\hline Hungary & $v$ & $u$ & $\theta$ & $\tau_{\mathrm{w}}$ & $s t$ & $p$ \\
\hline$v$ & 1 & & & & & \\
\hline$u$ & -0.67 & 1 & & & & \\
\hline$\theta$ & 0.91 & -0.91 & 1 & & & \\
\hline$\tau_{\mathrm{w}}$ & 0.68 & -0.99 & 0.98 & 1 & & \\
\hline$s t$ & 0.56 & 0.32 & 0.41 & -0.32 & 1 & \\
\hline$p$ & 0.69 & -0.1 & 0.41 & 0.89 & -0.2 & 1 \\
\hline Std. Dev. & 0.12 & 0.12 & 0.23 & 0.14 & 0.03 & 0.05 \\
\hline Autocorr & 0.96 & 0.93 & 0.94 & 0.92 & 0.97 & 0.89 \\
\hline Poland & $v$ & $u$ & $\theta$ & $\tau_{\mathrm{w}}$ & $s t$ & $p$ \\
\hline$v$ & 1 & & & & & \\
\hline$u$ & -0.98 & 1 & & & & \\
\hline$\theta$ & 0.99 & -0.99 & 1 & & & \\
\hline$\tau_{\mathrm{w}}$ & 0.98 & -0.99 & 0.99 & 1 & & \\
\hline$s t$ & 0.92 & -0.86 & 0.9 & 0.85 & 1 & \\
\hline$p$ & 0.95 & -0.98 & 0.9 & 0.98 & 0.78 & 1 \\
\hline Std. Dev. & 0.16 & 0.13 & 0.29 & 0.17 & 0.04 & 0.07 \\
\hline Autocorr & 0.92 & 0.91 & 0.92 & 0.9 & 0.96 & 0.89 \\
\hline
\end{tabular}

Note: The results are reported in logs as a trend of the HP filter with $\lambda=1600$. These are averages of 10,000 benchmark model simulations. 
which also corresponds to the empirical facts. Proper results were obtained for the job-finding rate, which generated proper correlation signs for most variables and for most countries. However, differences can be observed here: as empirical negative $-d r$ correlation is characteristic of all economies, the model-generated series are biased in the case of Poland and show a positive relation.

A more in-depth analysis of the historical time-series shows that some variables in some countries are positively correlated, while in others a negative correlation is observed. It is especially characteristic of the productivity and job destruction rate, whose correlations differ across the three transition economies (compare, for example, the $p-v ; p-\theta ; p-\tau_{w} ; d r-u$ correlations in Table 2). The simulations results (Table 4) show that these subtle differences cannot easily be replicated by the model and that the results deviate from the empirical facts in this case.

The second point of the analysis included workers' earnings over the business cycle. In the outlined model, wage dispersion comes from the stochastic diversity of job-specific output. In an uncertain framework, a worker's income rises randomly together with the increase in job output (this can be seen in Equation 13). The empirical and simulated wage dispersions are plotted in Figure 5. The historical cumulative distribution function (CDF) for each country was computed using OECD annual data for 2000-2013. It presented average gross wages paid in the business sector. Simulated wage dispersion was computed on the basis of the mean value from 10,000 model simulations. Both distributions were normalised in the $[0,1]$ interval to obtain comparable results.

It can be noted that there are some differences in the empirical and simulated $\mathrm{CDF}$, especially in the 6-9 quintile of the distribution. In the 1-5 and 9-10 quintiles, simulated distribution converges to the empirical distribution and disparities are slight.

The Polish and Czech simulated wage dispersion analysis shows a closer match to the data than for the Hungarian simulated wage dispersion analysis. For these two countries, i.e. Poland and the Czech Republic, a good match can especially be noticed in the 1-4 quintile of the distribution. Simulated wages for Hungary are biased and overestimated - some improvement can be noticed only in the last quintile of the distribution.

For Poland, the model predicts that $46 \%$ of wages over the business cycle would not be higher than 0.398 (as compared to 0.396 in the official data). For the Czech Republic, the model estimated that $46 \%$ of wages would be below 0.402 ; in the data, the value is equal to 0.458 . In the case of Hungary, $46 \%$ of simulated wages were below 0.400 , as opposed to 0.532 observed in the data. 

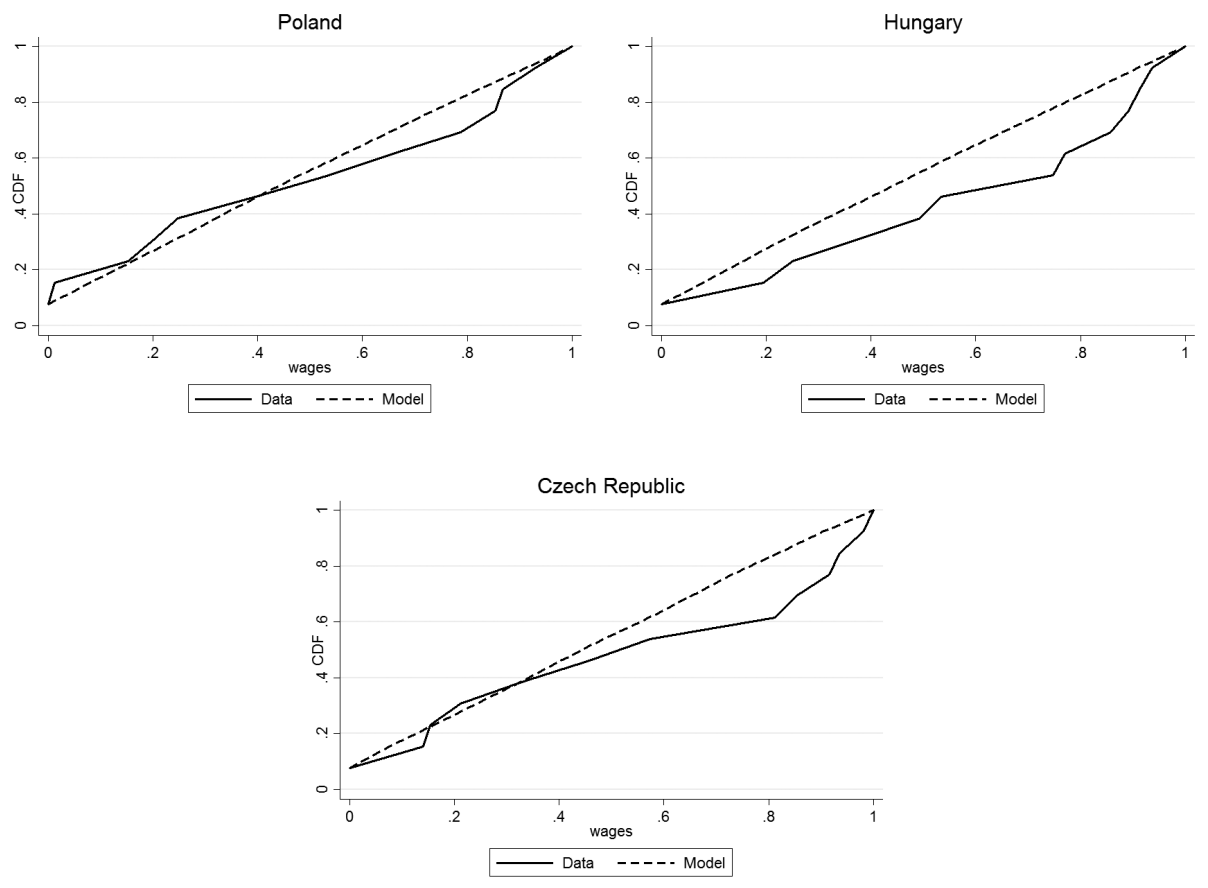

Figure 5. Empirical and simulated wage dispersion Source: Own calculations. Data were scaled according to the formula: $a_{i}=\frac{a_{i}-a_{i_{\min }}}{a_{i_{\max }}-a_{i_{\min }}}$; the min, $\max _{\text {indexes mean }}$ ine lowest and highest value of observations in each data set.

\section{CONCLUSIONS AND DISCUSSION}

This paper contributes to the literature of equilibrium unemployment models. A frictional framework with stochastic perturbations of the productivity process has been adopted for three post-socialist countries. The aim was to find whether the stochastic model with reasonable parameter calibration can replicate the differences in transition economy labour markets.

The first and foremost conclusion is that a specific design of the stochastic process under reasonable parameter calibration will result in considerable endogenous variable fluctuations, which are similar to the underlying real statistical data. Moreover, key correlation signs and autocorrelations of endogenous variables match the empirical data.

However, despite the strengths of the applied stochastic framework, there are some limitations. The main problem is the subtle differences between Polish, 
Czech and Hungarian labour market time-series, which implies that not all correlation signs across these three economies are coherent. This fact mainly concerns productivity and job destruction rate correlations with other variables. Despite specific calibration, the model was unable to simulate these subtle differences.

There are some distinguishing features of our paper. 1) This is the first time that the stochastic job search framework was successfully applied to an analysis of post-socialist countries. 2) Contrary to common studies using Markov chains, we implemented the discrete-time version of the GBM with the drift and volatility parameter to the model. 3) A unique model calibration strategy was developed, based solely on the author's own estimations. 4) The study underlines the role of stochastic calculus and its role in designing the shock mechanism in this class of partial equilibrium models.

\section{REFERENCES}

Abeille-Becker, C. - Clerc, P. (2013): The Cyclical Behavior of the Unemployment, Job Finding and Separation Rates. Revue Economique, 64(3): 519-526.

Acemoglu, D. (2011). Diversity and Technological Progress. In: The Rate and Direction of Inventive Activity Revisited. Cambridge: National Bureau of Economic Research.

Baxter, M. - King, R. (1999): Measuring Business Cycles: Approximate Band-Pass Filters for Economic Time Series. The Review of Economics and Statistics, 81(4): 575-593.

Becker, A. C. - Clerc, P. (2012): The Cyclical Behavior of the Unemployment, Job Finding and Separation Rates. Paris School ot Economics. Available on-line: http://sam2012.ucy.ac.cy/wpcontent/uploads/2012/05/Paper- Camille-Abeille-Becker.pdf

Benati, L. - Lubik, T. (2012): Sales, Inventories, and Real Interest Rates: A Century of Stylized Facts. Working Paper, No. 12-02, Federal Reserve Bank of Richmond.

Bukowski, M. - Kowal, P. - Lewandowski, P. (2011): Modelowa analiza rynków pracy o różnej strukturze instytucjonalnej (Modelling labour markets with different institutional structure). Warsaw: Institute for Structural Research.

Davis, S. - Haltiwanger, J. - Schuh, S. (1998): Job Creation and Destruction. ME: MIT Press.

Gatheral, J. - Schied, A. (2011): Optimal Trade Execution under Geometric Brownian Motion in the Almgren and Chriss Framework. International Journal of Theoretical and Applied Finance, 14(3): 353-368.

Gomis-Porqueras, P. - Benoit, J. - Chengsi, W. (2010): Optimal Monetary and Fiscal Policies in a Search-Theoretic Model of Money and Unemployment. MPRA Paper, No. 26262, University Library of Munich, Germany.

Hagedorn, M. - Manovskii, I. (2008): The Cyclical Behavior of Equilibrium Unemployment and Vacancies Revisited. American Economic Review, 98(4): 1692-1706.

Hodrick, R. J. - Prescott, E. C. (1997): Postwar U.S. Business Cycles: An Empirical Investigation. Journal of Money, Credit and Banking, 29(1): 1-16.

Hornstein, A. - Krusell, P. - Violante, G. (2011): Frictional Wage Dispersion in Search Models: A Quantitative Assessment. American Economic Review, 101(7): 2873-2898. 
Iossifov, P. (2014): Cross-Border Production Chains and Business Cycle Co-Movement between Central and Eastern European Countries and Euro Area Member States. Working Paper Series, No. 1628, European Central Bank.

Lamo, A. - Messina J. - Wasmer, E. (2011): Are Specific Skills an Obstacle to Labour Market Adjustment? Labour Economics, 18(2): 240-256.

Mortensen, D. (2005): Wage Dispersion: Why Are Similar Workers Paid Differently? Cambridge MA: The MIT Press.

Mortensen, D. - Nagypal, E. (2007): More on Unemployment and Vacancy Fluctuations. Review of Economic Dynamics, 10(3): 327-347.

Mortensen, D. - Pissarides, Ch. (1994): Job Creation and Job Destruction in the Theory of Unemployment. Review of Economic Studies, 61(3): 397-415.

Mortensen, D. - Pissarides, Ch. (1999): New Developments in Models of Search in the Labour Market. In: Ashenfelter, O. - Card, D. (eds): Handbook of Labour Economics. Elsevier, pp. 2567-2627.

Nakajima, M. (2012): Business Cycles in the Equilibrium Model of Labor Market Search and SelfInsurance. International Economic Review, 53(2): 399-432.

OECD (2012): OECD Employment Outlook 2012. OECD Publishing. http://dx.doi.org/10.1787/ empl_outlook-2012-en.

Pissarides, Ch. (2000): Equilibrium Unemployment Theory. 2nd Edition, Cambridge - Massachussets - London: The MIT Press.

Pissarides, Ch. (2011): Equilibrium in the Labour Market with Search Frictions. American Economic Review, 101(4): 1092-1105.

Prat, J. (2006): Job Separation under Uncertainty and the Wage Distribution. The B.E. Journal of Macroeconomics, De Gruyter, 6(1): 1-34.

Romer, D. (2012): Advanced Macroeconomics. New York: McGraw-Hill Comp.

Roszkowska, S. (2009): Aggregate Matching Function. The Case of Poland. Central European Journal of Economic Modelling and Econometrics, 1(2): 157-177.

Shimer, R. (2005): The Cyclical Behavior of Equilibrium Unemployment and Vacancies. American Economic Review, 95(1): 25-49.

Tokarski, T. (2005): Statystyczna analiza regionalnego zróżnicowania wydajności pracy, zatrudnienia i bezrobocia $w$ Polsce (Statistical analysis of labour productivity, employment and unemployment under spatial heterogeneity in Poland). Warsaw: Polish Economic Society.

Woźniak, M. (2015): Aktywne programy rynku pracy: szacunki funkcji dopasowan dla Polski z wykorzystaniem danych regionalnych (Active labour market programs: Some estimates of the matching function for Poland based on regional data). Ekonomista, 1: 15-41. 